\title{
Quantitative Ultrasound - An Epidemiological Tool to Uncover the Influence of Lifestyle Factors \& its Associated Co Morbidities on Bone Density
}

\author{
Joji Krishnan ${ }^{\text {a }}$ Mohamed Kunju Raffic ${ }^{\mathrm{b}}$, Kishore $\mathbf{S}^{\mathrm{a}}$ \\ a. Department of Orthopaedics, Government Medical College, Trivandrum, Kerala, India; \\ b. Department of Orthopaedics, Sree Gokulam Medical College, Venjaramood, Trivandrum, Kerala, India
}

Published on $1^{\text {st }}$ June 2020

\begin{abstract}
Osteoporosis, the metabolic disorder has become a global epidemic1 with increase in life expectancy and changing life style. Quantitative ultrasound is a cheap, non invasive, portable and convenient method to estimate bone strength without any radiation hazard.2-5 The aim of our study is to estimate the bone mineral density by using quantitative ultrasound, look for the influence of parameters like lifestyle factors, comorbidities, chronic drug intake, and other risk factors on BMD; and compare the results with those in the literature done with DEXA scans. In our study of 516 subjects, (i) BMD measures varied from -5.6 to +.5 .55 with a mean of -1.8 . (ii) BMD decreased significantly with age $(\mathrm{r}=.351, \mathrm{p}<0.0001)$, (iii) Low BMD was associated with increase in Fragility fractures ( $\mathrm{p}=.007)$ (iv) Antacid intake, which was pretty common in our subjects $(28.7 \%)$ led to decrease in BMD ( $\mathrm{p}<.005)$. (v) Diabetes significantly reduced BMD ( $<<.005)$. (vi) Increase in BMI led to significant increase in BMD ( $\mathrm{r}=.166, \mathrm{p}<.0001)$. (vii) BMD increased significantly with increase in physical activity $(\mathrm{r}=.148, \mathrm{p}<.001)$. Most of the associations found in our study, except that with diabetes, were similar to those consistently associated with BMD as measured with DEXA scans.6-15 Our study suggests the use of Quantitative ultrasound as powerful epidemiological tool with similar outcome measures to DEXA scan without any radiation hazards.
\end{abstract}

Key Words: Quantitative Ultrasound, BMD, Lifestyle Diseases, BMI, Drug Intake

\section{INTRODUCTION}

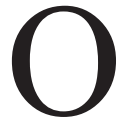

steoporosis, the metabolic disorder has become a global epidemic ${ }^{1}$ with increase in life expectancy and changing life style. There is an increase in the prevalence of osteoporosis and low bone mass of younger adults $^{16}$ in recent times owing to increasing substance abuse and sedentary lifestyle. ${ }^{17}$ Osteoporosis, being a silent epidemic, ${ }^{18}$ receives much less attention than it deserves and remain asymptomatic till a fracture occurs. Lack of affordability and access to available preventive treatment options leads to major gaps in the diagnosis and management of osteoporosis. ${ }^{19,20}$ Quantitative ultrasound is a cheap, non invasive, portable and convenient method to estimate bone strength without any radiation hazard..$^{2-5}$ The objective of our study is to estimate the bone mineral density by using quantitative ultrasound, and to look for the influence of parameters like lifestyle factors, comorbidities, chronic drug intake, and other risk factors on BMD; and compare the results with those done with DEXA scan ${ }^{21}$ which is the gold standard.

\section{MATERIALS AND METHODS}

The study data were taken from subjects attending the orthopaedic outpatient clinic and underwent Quantitative Ultrasound measurement of calcaneus. Ultrasound (US) technique for evaluating skeletal status used Speed of sound (SOS) and broadband ultrasound attenuation (BUA) properties assess bone strength and fragility. Census method was used on the specified days assigned for the study. Their anthropometric measurements, information on lifestyle factors (physical activity, alcohol intake, smoking, fragility fractures) and Co-morbidities like asthma, epilepsy, diabetes, hypothyroidism were documented as a structured questionnaire. Data was entered in excel

Cite this article as: Krishnan J, Raffic MK, S K. Quantitative Ultrasound - An Epidemiological Tool to Uncover the Influence of Lifestyle Factors \& its Associated Co Morbidities on Bone Density. KJOrth. 2020 Jun 1;33(01):8-12. 


\begin{tabular}{ccc}
\hline Table 1. Gender distribution & & \\
\hline Sex & Frequency & Percent \\
\hline Male & 284 & 55 \\
\hline Female & 232 & 45 \\
\hline Total & 516 & 100 \\
\hline
\end{tabular}

\begin{tabular}{|c|c|c|c|c|}
\hline Paramerers & N & Mean & Min & $\operatorname{Max}$ \\
\hline Age & 516 & 52.2 & 18 & 84 \\
\hline BMI & 516 & 25.8 & 15.42 & 45.49 \\
\hline Speed of Sound & 516 & 1548 & 1421 & 1649 \\
\hline Age at menopause & 232 & 46.19 & 30 & 59 \\
\hline Physical Activity & 516 & 2.06 & 0 & 10 \\
\hline BMD & 516 & -1.8 & -5.6 & 5.55 \\
\hline
\end{tabular}

\begin{tabular}{ccc}
\hline Table 3. BMD Patterns & & \\
\hline BMD & Frequency & Percent \\
\hline$<-2.5$ & 191 & 37.0 \\
\hline$-2.5--1$ & 190 & 36.8 \\
\hline$>-1$ & 135 & 26.2 \\
\hline Total & 516 & 100.0 \\
\hline
\end{tabular}

sheet and analysed using SPSS software. Characteristics of study subjects were depicted as numbers (percentages) for categorical variables, and mean+/- SD for continuous variables. Chi-square test $\left(\chi^{2}\right)$, Pearsons correlation and binary logistic regression analysis was used to look for associations as appropriate. $\mathrm{p}<.05$ was considered statistically significant for all statistical tests.

\section{RESULTS}

There were 516 subjects in our study, of which $55 \%$ were males and 45\%females (Table 1). Mean age of study population was 52years (18yrs-84 yrs). Physical activity varied from no exercise to maximum of $10 \mathrm{hrs} /$ day (mean of 2 hours). BMI varied from 15.4 to 45 (mean of 25.8). The age at menopause for women varied from 30 years to 59 years with mean of $46 \mathrm{yrs}$ (Table 2). The BMD measures varied from -5.6 to +.5 .55 with a mean of -1.8 .26$ $\%$ (35subjects) had normal BMD whereas osteoporosis and osteopaenia were seen in 37\% each (Table 3).

\section{BMD and Age}

Pearson correlation to look for association of BMD with age showed that BMD decreased significantly with age $(\mathrm{r}=.351, \mathrm{p}<0.0001)$ (Table 3a). This was however significantly different for males and females $p<0.016$ (Figure 1). After the age of 40, we found that the BMD decreases rapidly in females as compared to males. Binary logistic regression model for BMD also showed strongest association of decrease in BMD with increasing age

\begin{tabular}{ccc}
\multicolumn{2}{c}{ Table 3a. Correlation of BMD to Parameters } & \\
Parameters & Persons Correlation $(r)$ & P Value \\
Age & $-.351^{\star *}$ & 0.000 \\
\hline BMl & $.166^{\star *}$ & 0.000 \\
\hline Speed of sound & $.106^{\star}$ & 0.016 \\
\hline Physical activity & $.148^{\star}$ & 0.001 \\
\hline
\end{tabular}

\begin{tabular}{ccc} 
Table 4. Distribution of Comorbidities \& Lifestyle & \\
& Number of patients & Percent \\
\hline Asthma/COPD & 60 & $11.6 \%$ \\
\hline Hypothyrodism & 41 & $7.9 \%$ \\
\hline Epilepsy & 5 & $1 \%$ \\
\hline Diabetes & 130 & $25.2 \%$ \\
\hline Smoking & 31 & $6 \%$ \\
\hline Alcohol & 36 & $7 \%$ \\
\hline Antacid intake & 148 & $28.7 \%$ \\
\hline
\end{tabular}

\begin{tabular}{|c|c|c|c|c|c|}
\hline \multirow{2}{*}{\multicolumn{2}{|c|}{ Factors }} & \multirow{3}{*}{$\begin{array}{c}N \\
126\end{array}$} & \multicolumn{2}{|c|}{ BMD } & \multirow{4}{*}{$\begin{array}{l}\text { P Value } \\
0.016\end{array}$} \\
\hline & & & Mean & SD & \\
\hline \multirow{2}{*}{ Gender } & Male & & -1.537 & 1.523 & \\
\hline & Female & 390 & -1.934 & 1.625 & \\
\hline \multirow{2}{*}{ Smoking } & Absent & 485 & -1.844 & 1.613 & \multirow{2}{*}{0.688} \\
\hline & Present & 31 & -1.724 & 1.552 & \\
\hline \multirow{2}{*}{ Alcohol } & Absent & 480 & -1.857 & 1.610 & \multirow{2}{*}{0.307} \\
\hline & Present & 36 & -1.572 & 1.584 & \\
\hline \multirow{2}{*}{$\begin{array}{l}\text { Antacid } \\
\text { Intake }\end{array}$} & Absent & 368 & -1.710 & 1.641 & \multirow{2}{*}{0.004} \\
\hline & Present & 148 & -2.153 & 1.481 & \\
\hline \multirow{2}{*}{$\begin{array}{l}\text { History of } \\
\text { Fragility \# }\end{array}$} & Absent & 377 & -1.721 & 1.584 & \multirow{2}{*}{0.007} \\
\hline & Present & 139 & -2.150 & 1.637 & \\
\hline \multirow{2}{*}{$\begin{array}{l}\text { Asthma/ } \\
\text { COPD }\end{array}$} & Absent & 456 & -1.835 & 1.642 & \multirow{2}{*}{0.943} \\
\hline & Present & 60 & -1.851 & 1.335 & \\
\hline \multirow{2}{*}{$\begin{array}{l}\text { Hypothy- } \\
\text { roidism }\end{array}$} & Absent & 475 & -1.850 & 1.617 & \multirow{2}{*}{0.545} \\
\hline & Present & 41 & -1.624 & 1.569 & \\
\hline \multirow{2}{*}{ Epilepsy } & Absent & 511 & -1.830 & 1.605 & \multirow{2}{*}{0.355} \\
\hline & Present & 5 & -2.500 & 1.968 & \\
\hline \multirow{2}{*}{ Diabetes } & Absent & 386 & -1.951 & 1.499 & \multirow{2}{*}{0.005} \\
\hline & Present & 130 & -1.498 & 1.862 & \\
\hline
\end{tabular}

$(p<0.0001)$. Though BMD decreased significantly after menopause, there was no significant association of age at menopause and BMD trends.

\section{BMD and Fragility Fractures}

There was significant association between decrease in BMD with increase in Fragility fracture occurrence $(p=.007)$. The average BMD of patients sustaining fragility fractures was -2.150 , as compared to -1.721 in subjects without fragility fractures. The common fragility fractures noted were at wrist, hip \& spine. 


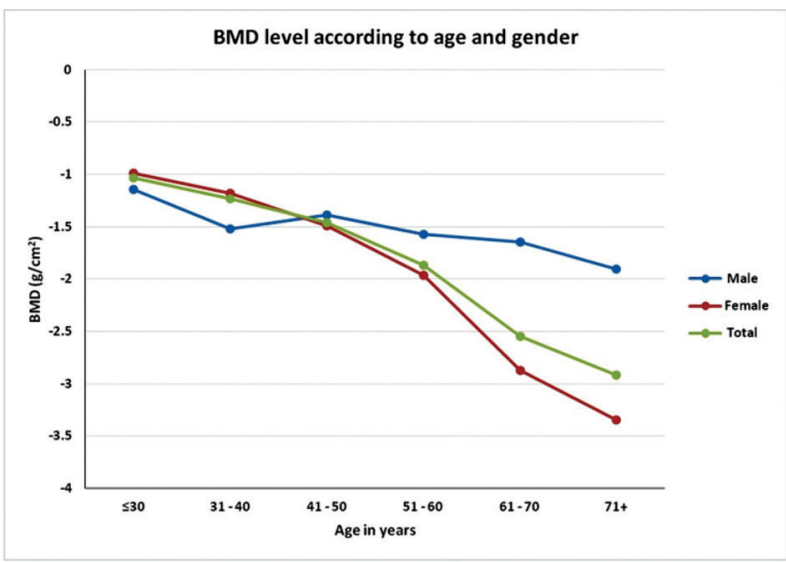

Figure 1. BMI v/s Age (In Males \& Females)

\section{BMD and Antacid Intake}

Antacid intake, which was pretty common in our subjects $(28.7 \%)$ led to decrease in BMD. The mean BMD value of subjects with regular antacid intake was -2.153 as compared to -1.710 in subjects without antacid intake; and the association was significant $(\mathrm{p}=.004)$, suggesting that chronic antacid intake would weaken our bones (Figure1a).

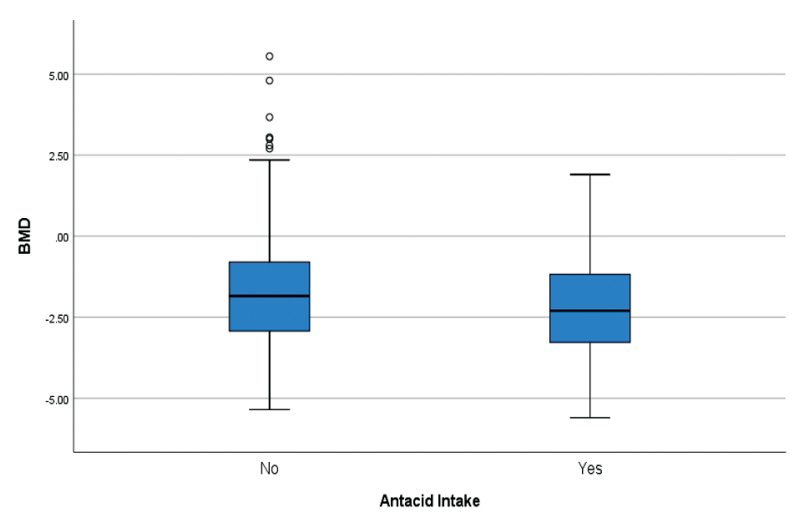

Figure 1a. Association of BMD to Antacid Intake

\section{BMD \& Risk Factors}

Diabetes $(25.2 \%)$ was the most common co morbidity (Figure 2). The mean BMD of the diabetic group was -1.95 as compared to -1.49 in non-diabetic group, suggesting that diabetes significantly reduced BMD $(\mathrm{p}<.005)$. Alcohol intake and smoking were seen in only $6 \% \& 7 \%$ respectively as the study population had only $25 \%$ males. Other co morbidities observed were asthma/ COPD, hypothyroidism, epilepsy \& diabetes (Table 4). However, their numbers being small were not enough to show any statistical significance (Table 5).

\section{BMD, Physical Activity \& Body Mass Index (BMI)}

Increase in BMI led to significant increase in BMD $(r=.166, p<.0001)$ Figure 4. The scatter plot showing

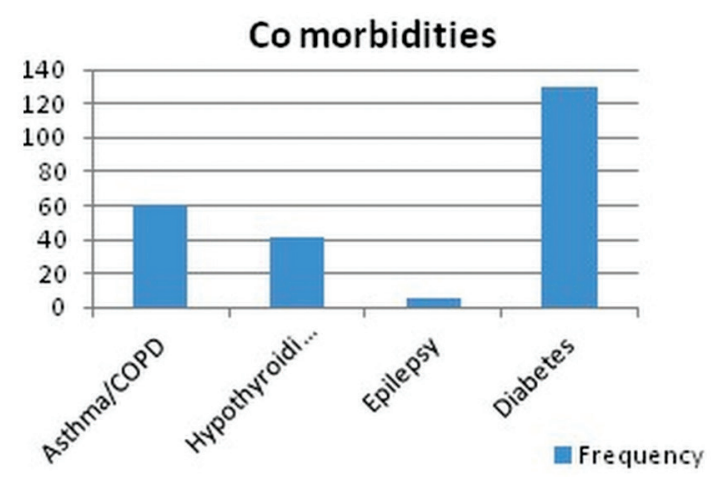

Figure 2. Distribution of Comorbidities in Subjects

increase in BMD with BMI is shown in fig X. Available studies have provided contrasting findings: some authors suggest that obesity has detrimental effects on bone health, while others have revealed its potential protective role. ${ }^{14,15}$

BMD increased significantly with increase in physical activity $(\mathrm{r}=.148, \mathrm{p}<.001)$. ROC curve with optimum cut off at .75 hours ( $45 \mathrm{mts}$ ) showed area under the curve $57.4 \%$ with $95 \%$ confidence interval of .53 to .617 , suggesting that physical activity of more than 45 minutes per day led to significant increase in BMD (Figure 3).

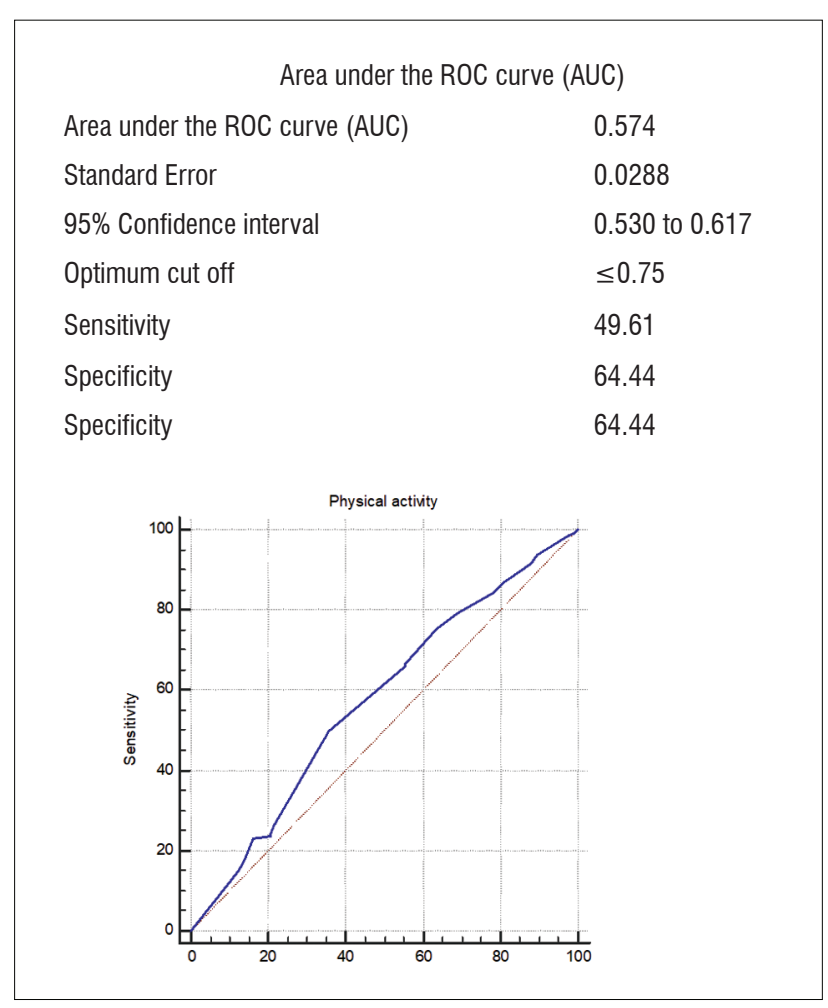

Figure 3. ROC Curve: Physical Activity-BMD

\section{DISCUSSION}

In our study, we found that the bone strength measured using calcaneal ultrasound had significant positive association with physical activity ( $>45 \mathrm{mts} /$ day), and Body mass index. 

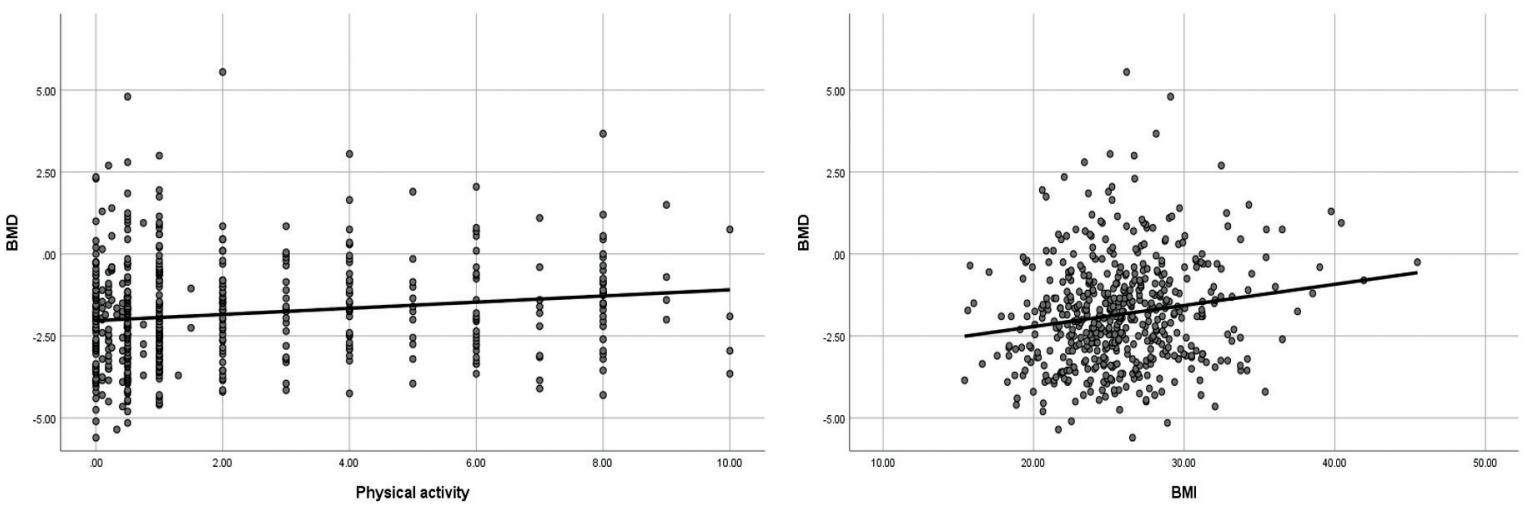

Figure 4. Scatter diagram to show changes of BMD with physical activity and BMI

Increasing age, antacid intake, fragility fractures \& diabetes showed inverse association with Bone strength. QUS measurements were in the direction of higher values in men as compared to women. Most of the associations found in our study, except with diabetes, were similar to those consistently associated with BMD as measured with DEXA scans. ${ }^{6-15}$ Diabetes and bone strength depends on the type of diabetes, T1DM presenting with decreased BMD while patients with T2DM presenting with normal to increased BMD. ${ }^{22,23}$ Our study, which included T1DM and T2DM in a single group, showed decrease in BMD as an association to diabetes.

Despite its proven advantages including simplicity of use, low cost, portability and safety; the use of QUS remains controversial and has its limitations. Bone size and geometry, soft tissue thickness, and anthropometric findings have its effect on QUS values. ${ }^{24,25}$ This is the major limitation of our study.

\section{CONCLUSION}

Quantitative ultrasound (QUS) is a cheap, non invasive, portable and convenient tool to estimate bone strength in our community. Our study suggests the use of Quantitative ultrasound as powerful cost effective epidemiological surveillance tool, with similar outcome measures to DEXA scan, without any radiation hazards. Considering the availability and cheap nature of this technique, it can be used as an ideal tool for mass screening of osteoporosis in our setup.

\section{END NOTE}

\section{Author Information}

1. Dr Joji Krishnan, Assistant Professor, Department of Orthopaedics, Government Medical College, Trivandrum, Kerala, India.

2. Prof Mohamed Kunju Raffic, Prof \& Head, Department of Orthopaedics, Sree Gokulam Medical College, Venjaramood, Trivandrum, Kerala, India
3. Dr Kishore S, Additional professor, Department of Orthopaedics, Government Medical College, Trivandrum, Kerala, India.

\section{Conflict of Interest: None declared}

\section{REFERENCES}

1. Sözen T, Özışık L, Başaran NÇ. An overview and management of osteoporosis. Eur J Rheumatol. 2017 Mar;4(1):46-56.

2. Pisani P, Renna MD, Conversano F, Casciaro E, Muratore M, Quarta E, et al. Screening and early diagnosis of osteoporosis through X-ray and ultrasound based techniques. World J Radiol. 2013 Nov 28;5(11):398-410.

3. Quiros Roldan E, Brianese N, Raffetti E, Focà E, Pezzoli MC, Bonito A, et al. Comparison between the gold standard DXA with calcaneal quantitative ultrasound based-strategy (QUS) to detect osteoporosis in an HIV infected cohort. Braz J Infect Dis. 2017 Dec;21(6):581-6.

4. Chen, S.-J. et al. Comparisons of Different Screening Tools for Identifying Fracture/Osteoporosis Risk Among Community-Dwelling Older People. Medicine (Baltimore) 2016 May; 95(20)

5. Constant D, Rosenberg L, Zhang Y, Cooper D, Kalla AA, Micklesfield L, et al. Quantitative ultrasound in relation to risk factors for low bone mineral density in South African pre-menopausal women. Arch Osteoporos. 2009 Dec;4(1-2):55-65.

6. Berger C, Langsetmo L, Joseph L, Hanley DA, Davison KS, Josse R, et al. Change in bone mineral density as a function of age in women and men and association with the use of antiresorptive agents. CMAJ. 2008 Jun 17;178(13):1660-8.

7. Naganathan V, Sambrook P. Gender differences in volumetric bone density: a study of opposite-sex twins. Osteoporos Int. 2003 Jul;14(7):564-9.

8. Alghadir AH, Gabr SA, Al-Eisa E. Physical activity and lifestyle effects on bone mineral density among young adults: sociodemographic and biochemical analysis. J Phys Ther Sci. 2015 Jul;27(7):2261-70.

9. Carter MI, Hinton PS. Physical activity and bone health. Mo Med. 2014 Feb;111(1):59-64.

10. Panday K, Gona A, Humphrey MB. Medication-induced osteoporosis: screening and treatment strategies. Ther Adv Musculoskelet Dis. 2014 Oct;6(5):185-202.

11. Dey M, Bukhari M. Predictors of fragility fracture and low bone mineral density in patients with a history of parental fracture. Osteoporos Sarcopenia. 2019 Mar;5(1):6-10.

12. Posen J, Beaton DE, Sale J, Bogoch ER. Bone mineral density testing after fragility fracture. Can Fam Physician. 2013 Dec;59(12):e564-71. 
13. Montazerifar F, Karajibani M, Alamian S, Sandoughi M, Zakeri $Z$, et al. Age, Weight and Body Mass Index Effect on Bone Mineral Density in Postmenopausal Women, Health Scope. 2014 ; 3(2):e14075.

14. Kumar A, Sharma AK, Mittal S, Kumar G. The Relationship Between Body Mass Index and Bone Mineral Density in Premenopausal and Postmenopausal North Indian Women. J Obstet Gynaecol India. $2016 \mathrm{Feb}$;66(1):52-6.

15. Palermo A, Tuccinardi D, Defeudis G, Watanabe M, D'Onofrio L, Lauria Pantano A, et al. BMI and BMD: The Potential Interplay between Obesity and Bone Fragility. Int J Environ Res Public Health. 2016 May 28;13(6).

16. Osteoporosis cases increase among younger adults | The Source | Washington University in St. Louis [Internet]. The Source. 2004 [cited $2021 \mathrm{Feb} 7$ ].

17. Hamrick I, Schrager S, Nye AM. Treatment of osteoporosis: current state of the art. Wien Med Wochenschr. 2015 Feb;165(3-4):54-64

18. Kanis J. Osteoporosis--the silent epidemic. Health Visit. 1989 Jan;62(1):14-5.

19. Khadilkar AV, Mandlik RM. Epidemiology and treatment of osteo- porosis in women: an Indian perspective. Int J Womens Health. 2015 Oct 19;7:841-50.

20. Lems WF, Raterman HG. Critical issues and current challenges in osteoporosis and fracture prevention. An overview of unmet needs. Ther Adv Musculoskelet Dis. 2017 Dec;9(12):299-316.

21. Morgan SL, Prater GL. Quality in dual-energy X-ray absorptiometry scans. Bone. 2017 Nov;104:13-28.

22. Sundararaghavan V, Mazur MM, Evans B, Liu J, Ebraheim NA. Diabetes and bone health: latest evidence and clinical implications. Ther Adv Musculoskelet Dis. 2017 Mar;9(3):67-74.

23. Valderrábano RJ, Linares MI. Diabetes mellitus and bone health: epidemiology, etiology and implications for fracture risk stratification. Clin Diabetes Endocrinol. 2018;4:9.

24. Baroncelli GI. Quantitative Ultrasound Methods to Assess Bone Mineral Status in Children: Technical Characteristics, Performance, and Clinical Application. Pediatric Research. 2008 Mar;63(3):220-8.

25. Guglielmi G, Scalzo G, de Terlizzi F, Peh WCG. Quantitative ultrasound in osteoporosis and bone metabolism pathologies. Radiol Clin North Am. 2010 May;48(3):577-88. 